\title{
Glutathione-Functionalized Organosilicon Oxide Nanoparticles for Bioimaging and Forensics
}

Apurav Guleria ${ }^{a^{*}}$, Ashlesha P. Chavan ${ }^{b}$, Suman Neogy ${ }^{c}$, V. V. Gandhi ${ }^{d}$, Amit Kunwara, Anil K. Debnath ${ }^{\mathrm{e}}$, and Soumyakanti Adhikaria*

${ }^{a}$ Radiation \& Photochemistry Division, Bhabha Atomic Research Centre, Mumbai 400085, India ${ }^{b}$ KJSCE, Vidyavihar, Mumbai 400077, India

'Materials Science Division, Bhabha Atomic Research Centre, Mumbai 400085, India

${ }^{d}$ Homi Bhabha National Institute, Trombay, Mumbai 400094, India

eTechnical Physics Division, Bhabha Atomic Research Centre, Mumbai 400085, India

*Corresponding author email: aguleria@barc.gov.in \& asoumya@barc.gov.in,

Tel: (+91)-22-25590919, (+91)-22-25590301

\section{Supporting Information:}<smiles>CO[Si](C)(CCCN)OC</smiles>

Fig.S1. Molecular structure of (3-Aminopropyl) trimethoxysilane (APTS).
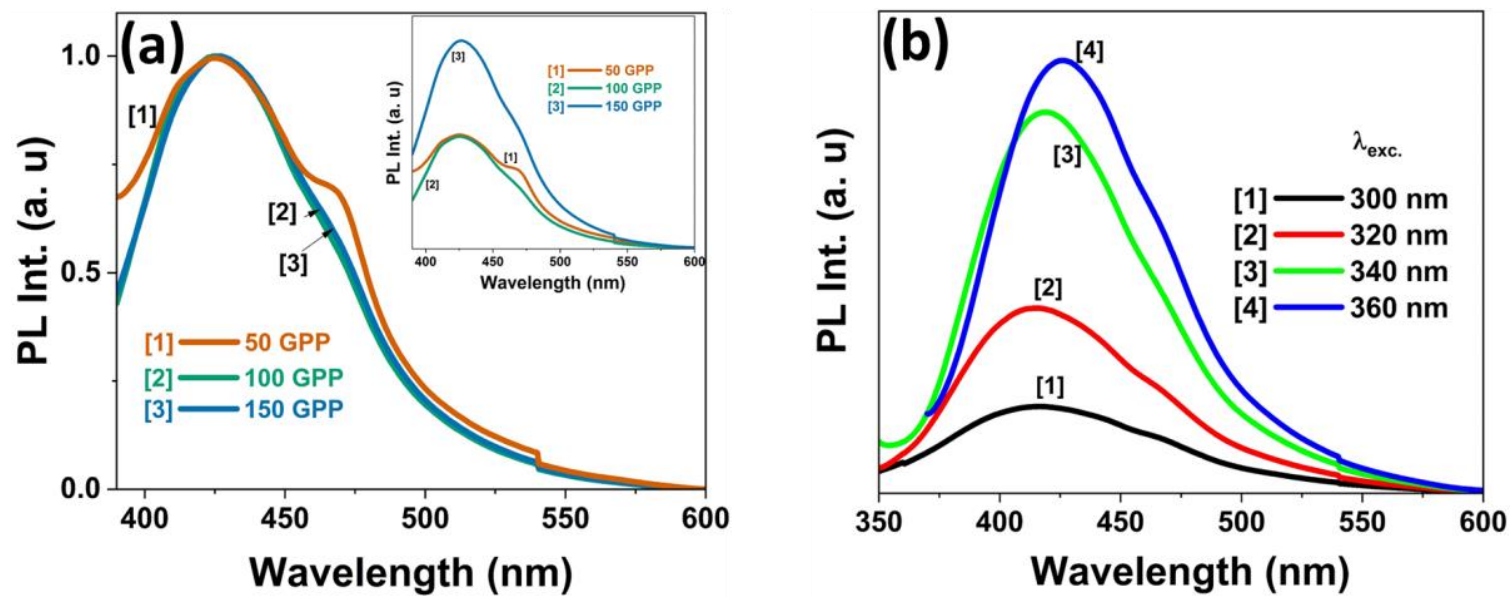

Fig.S2. (a) Normalized room temperature PL spectra $\left(\lambda_{\mathrm{ex}}=360 \mathrm{~nm}\right)$ of OSiNPs synthesized by electron beam irradiation with different dose rates, while absorbed dose and [APTS] were kept constant at $10 \mathrm{kGy}$ and $25 \mathrm{mM}$, respectively. Inset shows the corresponding unnormalized PL spectra; (b) Room temperature 
excitation-wavelength-dependent PL spectra of OSiNPs synthesized with an absorbed dose of $\sim 60 \mathrm{kGy}($ dose rate $=100 \mathrm{GPP} ;[$ APTS $]=100 \mathrm{mM})$.
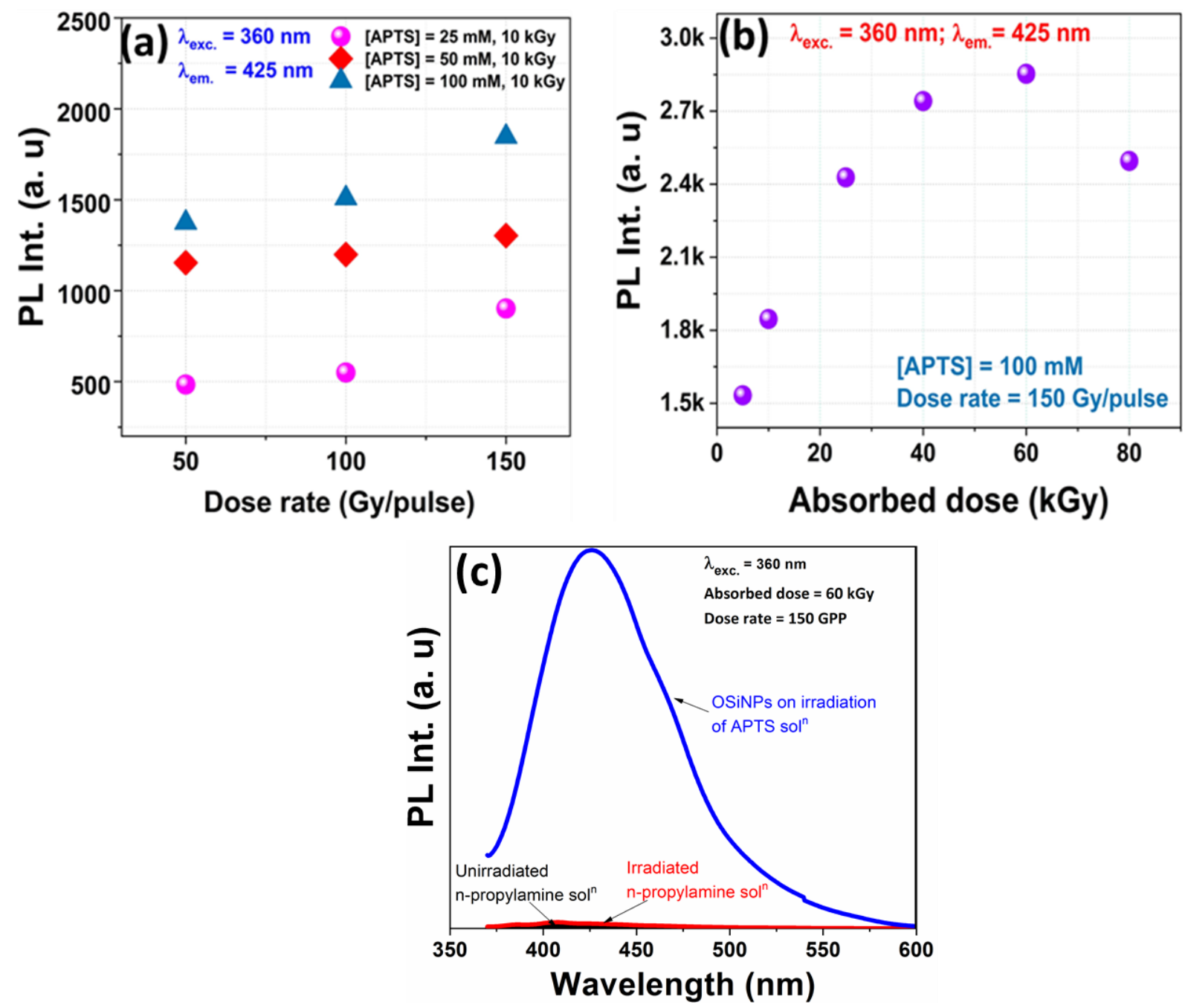

Fig.S3. (a) Effect of dose rate and precursor concentration on the PL intensity of OSiNPs synthesized with an absorbed dose of $10 \mathrm{kGy}$; (b) Effect of absorbed dose on the PL intensity of OSiNPs, while dose rate and precursor concentration were kept constant at $150 \mathrm{GPP}$ and $100 \mathrm{mM}$, respectively; (c) Control experiment (to rule out the formation of fluorescent carbon NPs), where an aqueous mixture of n-propylamine (major component in the molecular structure of APTS) was 
irradiated. No PL was observed in the aqueous solution of n-propylamine on irradiation.

Table S1: Absolute QE and average lifetime values $(\langle\tau\rangle$, ns) of OSiNPs at various precursor concentrations ([APTS]). (Experimental parameters: absorbed dose $=60 \mathrm{kGy}$, dose rate $=150$ GPP, LED excitation wavelength $\left(\lambda_{\text {ex }}\right)=339 \mathrm{~nm}$; the measurements were carried out at room temperature, i.e., $\left.20 \pm 2{ }^{\circ} \mathrm{C}\right)$.

\begin{tabular}{|c|c|c|c|c|c|c|c|c|c|c|}
\hline $\begin{array}{c}\text { [APTS }] \\
(\mathbf{m M})\end{array}$ & $\begin{array}{c}\text { Absolute } \\
\text { QE }\end{array}$ & $\begin{array}{c}\lambda_{\mathrm{em}} \\
(\mathrm{nm})\end{array}$ & $\begin{array}{l}\text { T1 } \\
\text { (ns) }\end{array}$ & $\mathbf{a}_{1}$ & $\begin{array}{l}\text { T2 } \\
\text { (ns) }\end{array}$ & $\mathbf{a}_{2}$ & $\begin{array}{l}\text { T3 } \\
\text { (ns) }\end{array}$ & $\mathbf{a} 3$ & $\begin{array}{l}\langle\tau\rangle \\
(\mathbf{n s})\end{array}$ & \\
\hline \multirow{2}{*}{$100 \mathrm{mM}$} & \multirow{2}{*}{$9 \%$} & 420 & 3.10 & 0.34 & 8.59 & 0.48 & 0.90 & 0.18 & 5.3 & 1.0 \\
\hline & & 480 & 3.75 & 0.37 & 9.74 & 0.42 & 1.07 & 0.20 & 5.7 & 1.0 \\
\hline \multirow{2}{*}{$50 \mathrm{mM}$} & \multirow{2}{*}{$\sim 5.2 \%$} & 420 & 1.74 & 0.31 & 6.93 & 0.50 & 0.12 & 0.19 & 4.0 & 1.2 \\
\hline & & 480 & 1.98 & 0.33 & 7.68 & 0.52 & 0.29 & 0.15 & 4.7 & 1.1 \\
\hline \multirow{2}{*}{$25 \mathrm{mM}$} & \multirow{2}{*}{ 3.7 \% } & 420 & 2.35 & 0.38 & 6.78 & 0.44 & 0.58 & 0.18 & 3.9 & 1.2 \\
\hline & & 480 & 1.89 & 0.35 & 6.94 & 0.53 & 0.27 & 0.12 & 4.4 & 1.2 \\
\hline \multirow{2}{*}{$10 \mathrm{mM}$} & \multirow{2}{*}{ 1.0\% } & 420 & 1.56 & 0.38 & 5.52 & 0.39 & 0.15 & 0.24 & 2.8 & 1.1 \\
\hline & & 480 & 1.98 & 0.42 & 6.73 & 0.41 & 0.23 & 0.18 & 3.6 & 1.1 \\
\hline
\end{tabular}


Table S2: Average lifetime values $(\langle\tau\rangle$, ns) of OSiNPs at various emission wavelengths $\left(\lambda_{\mathrm{em}}\right)$, while $\lambda_{\mathrm{ex}}=339 \mathrm{~nm}$. The measurements were carried out at room temperature, i.e., $20 \pm 2{ }^{\circ} \mathrm{C}$.

\begin{tabular}{|c|c|c|c|c|c|c|c|c|c|}
\hline $\begin{array}{c}\text { Absorbed } \\
\text { Dose }\end{array}$ & $\begin{array}{c}\lambda_{\mathrm{em}} \\
(\mathbf{n m})\end{array}$ & $\begin{array}{r}\text { T1 } \\
\text { (ns) }\end{array}$ & $\mathbf{a}_{1}$ & $\begin{array}{c}\text { T2(n } \\
\text { s) }\end{array}$ & $\mathbf{a}_{2}$ & $\begin{array}{c}\text { T3 } \\
\text { (ns) }\end{array}$ & $\mathbf{a} 3$ & $\begin{array}{l}\langle\tau\rangle \\
(\mathbf{n s})\end{array}$ & $\chi^{2}$ \\
\hline \multirow{2}{*}{$25 \mathrm{kGy}$} & 420 & 2.83 & 0.38 & 8.33 & 0.43 & 0.76 & 0.19 & 4.8 & 1.0 \\
\hline & 480 & 3.45 & 0.37 & 8.96 & 0.40 & 1.10 & 0.23 & 5.1 & 1.0 \\
\hline \multirow{2}{*}{40 kGy } & 420 & 3.28 & 0.36 & 8.59 & 0.41 & 0.98 & 0.22 & 4.9 & 1.0 \\
\hline & 480 & 3.06 & 0.38 & 8.79 & 0.44 & 0.86 & 0.18 & 5.2 & 1.1 \\
\hline \multirow{3}{*}{$60 \mathrm{kGy}$} & 420 & 3.10 & 0.34 & 8.59 & 0.48 & 0.90 & 0.18 & 5.3 & 1.0 \\
\hline & 480 & 3.75 & 0.37 & 9.74 & 0.42 & 1.07 & 0.20 & 5.7 & 1.0 \\
\hline & 530 & 2.05 & 0.30 & 8.15 & 0.53 & 1.47 & 0.16 & 5.3 & 1.1 \\
\hline \multicolumn{10}{|c|}{ HF treated OSiNPs (After 24 hrs of treatment) } \\
\hline \multirow{3}{*}{$60 \mathrm{kGy}$} & 420 & 2.53 & 0.33 & 9.16 & 0.56 & 0.50 & 0.11 & 6.0 & 1.1 \\
\hline & 480 & 3.41 & 0.33 & 10.6 & 0.51 & 0.93 & 0.16 & 6.4 & 1.0 \\
\hline & 530 & 3.19 & 0.34 & 10.3 & 0.50 & 0.85 & 0.16 & 6.4 & 1.0 \\
\hline \multicolumn{10}{|c|}{ L-Glu@OSiNPs } \\
\hline \multirow{3}{*}{$60 \mathrm{kGy}$} & 420 & 4.71 & 0.5 & 10.93 & 0.20 & 1.39 & 0.3 & 4.9 & 1.1 \\
\hline & 480 & 5.08 & 0.5 & 12.05 & 0.22 & 1.51 & 0.28 & 5.6 & 1.0 \\
\hline & 530 & 3.74 & 0.43 & 9.55 & 0.38 & 1.13 & 0.2 & 5.4 & 1.0 \\
\hline
\end{tabular}


Table S3: Temperature-dependent average lifetime values $(\langle\tau\rangle, n s)$ of OSiNPs (synthesized with an absorbed dose $=60 \mathrm{kGy}$, dose rate $=150 \mathrm{GPP},[\mathrm{APTS}]=$ $100 \mathrm{mM})$ at various emission wavelengths $\left(\lambda_{\mathrm{em}}\right)$, while the $\lambda_{\mathrm{ex}}=339 \mathrm{~nm}$. OSiNPs displayed tri-exponential decay traces and time constant values (T1, T2 \& T3) along with their amplitudes $\left(a_{1}, a_{2} \& a_{3}\right)$ have been tabulated.

\begin{tabular}{|c|c|c|c|c|c|c|c|c|c|}
\hline $\begin{array}{c}\lambda_{\mathrm{em}} \\
(\mathrm{nm})\end{array}$ & $\mathrm{T}\left({ }^{0} \mathrm{C}\right)$ & $\begin{array}{l}\text { T1 } \\
\text { (ns) }\end{array}$ & $\mathbf{a}_{1}$ & $\begin{array}{c}\text { T2 } \\
\text { (ns) }\end{array}$ & $\mathbf{a}_{2}$ & $\begin{array}{r}\text { T3 } \\
\text { (ns) }\end{array}$ & $\mathbf{a}_{3}$ & $\begin{array}{l}\langle\tau\rangle \\
\text { (ns) }\end{array}$ & $\chi^{2}$ \\
\hline \multirow{6}{*}{420} & 20 & 3.10 & 0.34 & 8.59 & 0.48 & 0.90 & 0.18 & 5.3 & 1.0 \\
\hline & 30 & 2.52 & 0.37 & 8.07 & 0.49 & 0.55 & 0.14 & 4.9 & 1.0 \\
\hline & 40 & 3.08 & 0.37 & 8.57 & 0.39 & 0.88 & 0.23 & 4.7 & 1.1 \\
\hline & 50 & 3.08 & 0.38 & 8.57 & 0.36 & 0.88 & 0.26 & 4.4 & 1.0 \\
\hline & 60 & 2.01 & 0.38 & 7.36 & 0.43 & 0.30 & 0.19 & 3.9 & 1.1 \\
\hline & 70 & 3.00 & 0.37 & 8.24 & 0.31 & 0.82 & 0.32 & 3.9 & 1.0 \\
\hline \multirow{6}{*}{480} & 20 & 3.75 & 0.37 & 9.74 & 0.42 & 1.07 & 0.20 & 5.7 & 1.0 \\
\hline & 30 & 3.41 & 0.38 & 9.13 & 0.41 & 1.01 & 0.22 & 5.2 & 1.0 \\
\hline & 40 & 2.64 & 0.39 & 8.39 & 0.43 & 0.70 & 0.18 & 4.7 & 1.0 \\
\hline & 50 & 2.15 & 0.39 & 7.73 & 0.46 & 0.38 & 0.15 & 4.4 & 1.1 \\
\hline & 60 & 3.44 & 0.37 & 8.98 & 0.32 & 1.04 & 0.31 & 4.4 & 1.1 \\
\hline & 70 & 2.68 & 0.36 & 7.86 & 0.35 & 0.78 & 0.28 & 3.9 & 1.0 \\
\hline
\end{tabular}



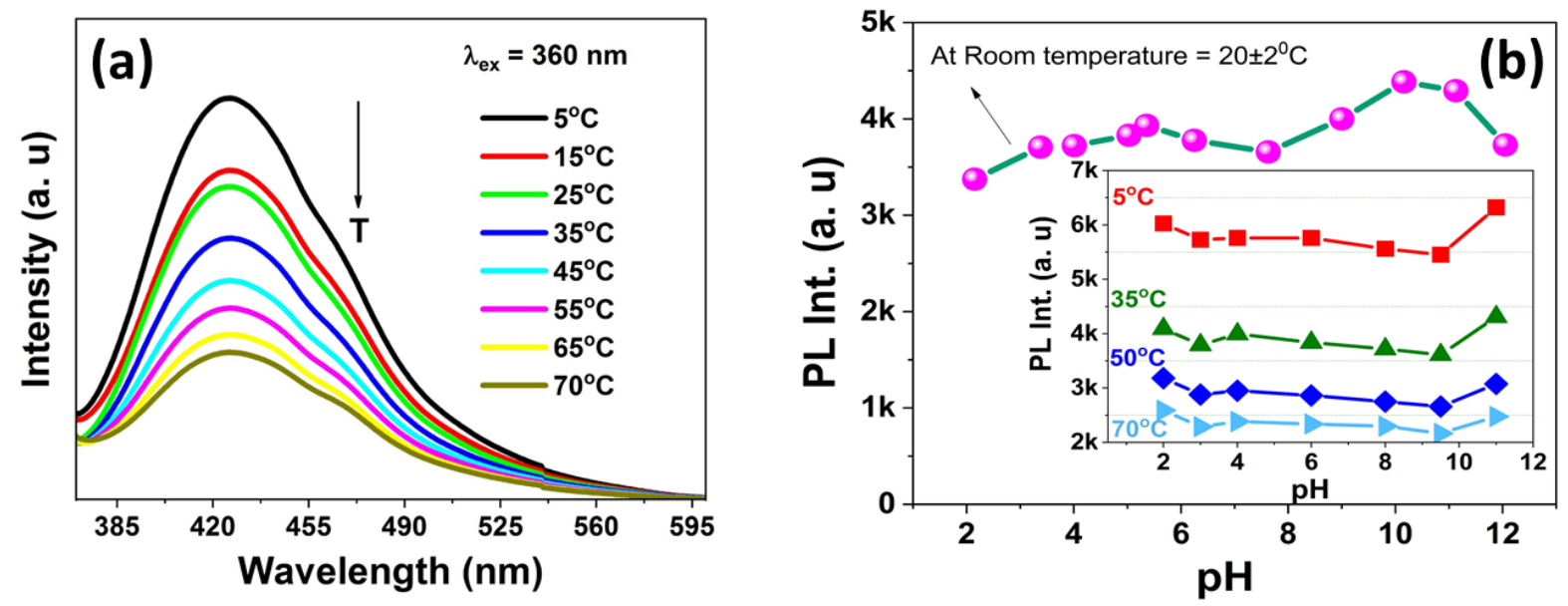

Fig.S4. (a) PL spectra of OSiNPs $\left(\lambda_{\mathrm{ex}}=360 \mathrm{~nm}\right.$; absorbed dose $\left.=60 \mathrm{kGy}\right)$ at various temperatures ranging from 5 to $70{ }^{\circ} \mathrm{C}$; (b) $\mathrm{pH}$ effect (measured at room temperature, i.e., $\left.20 \pm 2{ }^{\circ} \mathrm{C}\right)$ on the PL properties of OSiNPs $\left(\lambda_{\mathrm{ex}}=360 \mathrm{~nm}\right.$; absorbed dose $=60 \mathrm{kGy}$ ). Inset of (b): Spectra illustrating non-significant variations in the PL intensity of OSiNPs versus $\mathrm{pH}$ values $\left(\lambda_{\mathrm{ex}}=360 \mathrm{~nm}\right.$; absorbed dose $=60 \mathrm{kGy}$ ) measured at different temperatures (i.e., $5{ }^{\circ} \mathrm{C}, 35{ }^{\circ} \mathrm{C}, 50{ }^{\circ} \mathrm{C}$ and $\left.70{ }^{\circ} \mathrm{C}\right)$. 

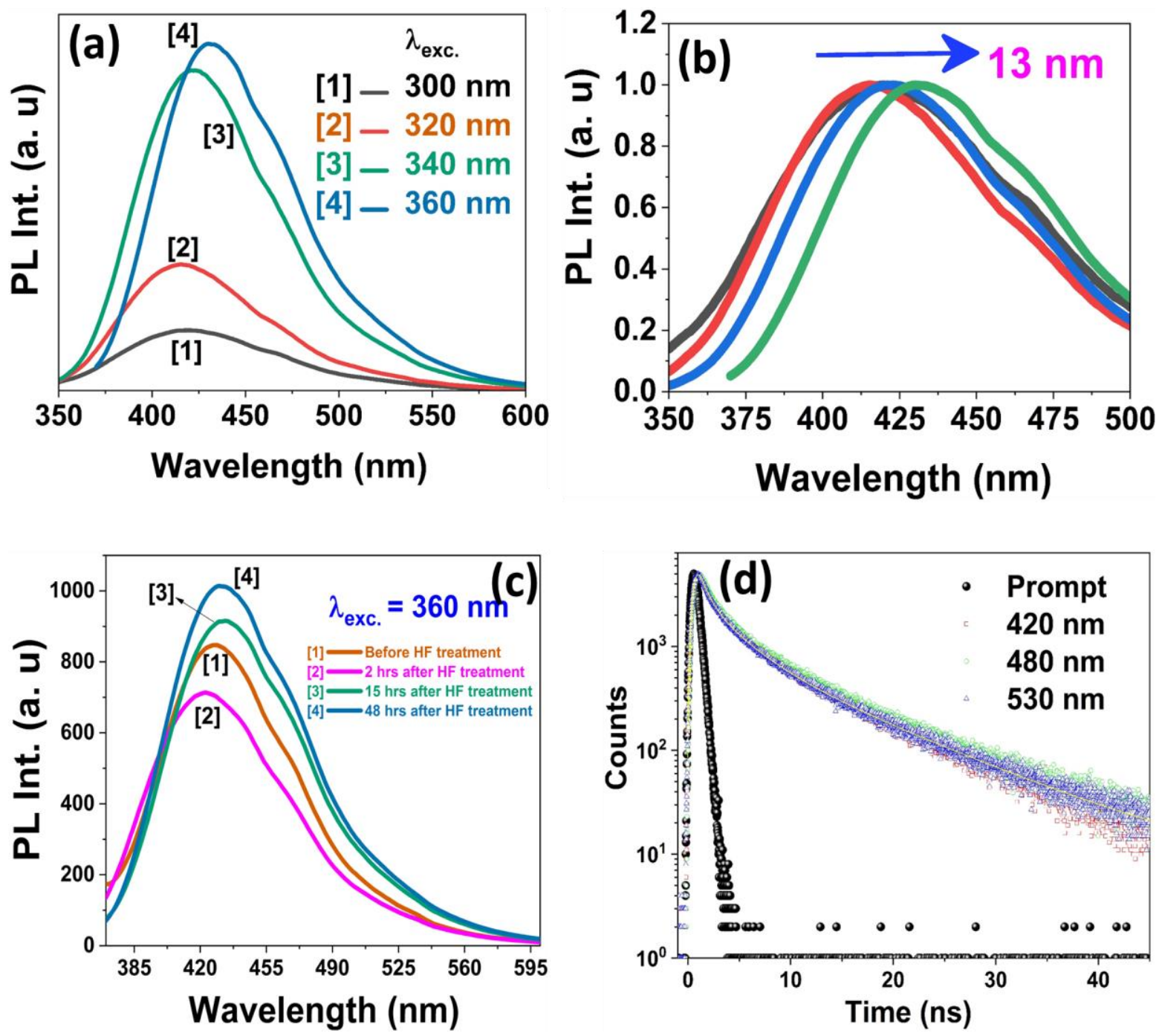

Fig.S5. (a) Room temperature excitation-wavelength-dependent PL spectra of OSiNPs (absorbed dose of $\sim 60 \mathrm{kGy}$ ) after $24 \mathrm{~h}$ of HF treatment; (b) Corresponding normalized PL spectra of the NPs displaying peak shift with the excitation wavelengths; (c) Comparative PL spectra of pre- and post-HF treated OSiNPs with time; (d) Room temperature PL temporal decay curves $\left(\lambda_{\mathrm{ex}}=339\right.$ $\mathrm{nm}$ ) for HF treated OSiNPs (after $24 \mathrm{~h}$ of treatment) at different emission wavelengths, along with the IRF (prompt) and the best fit curve. 


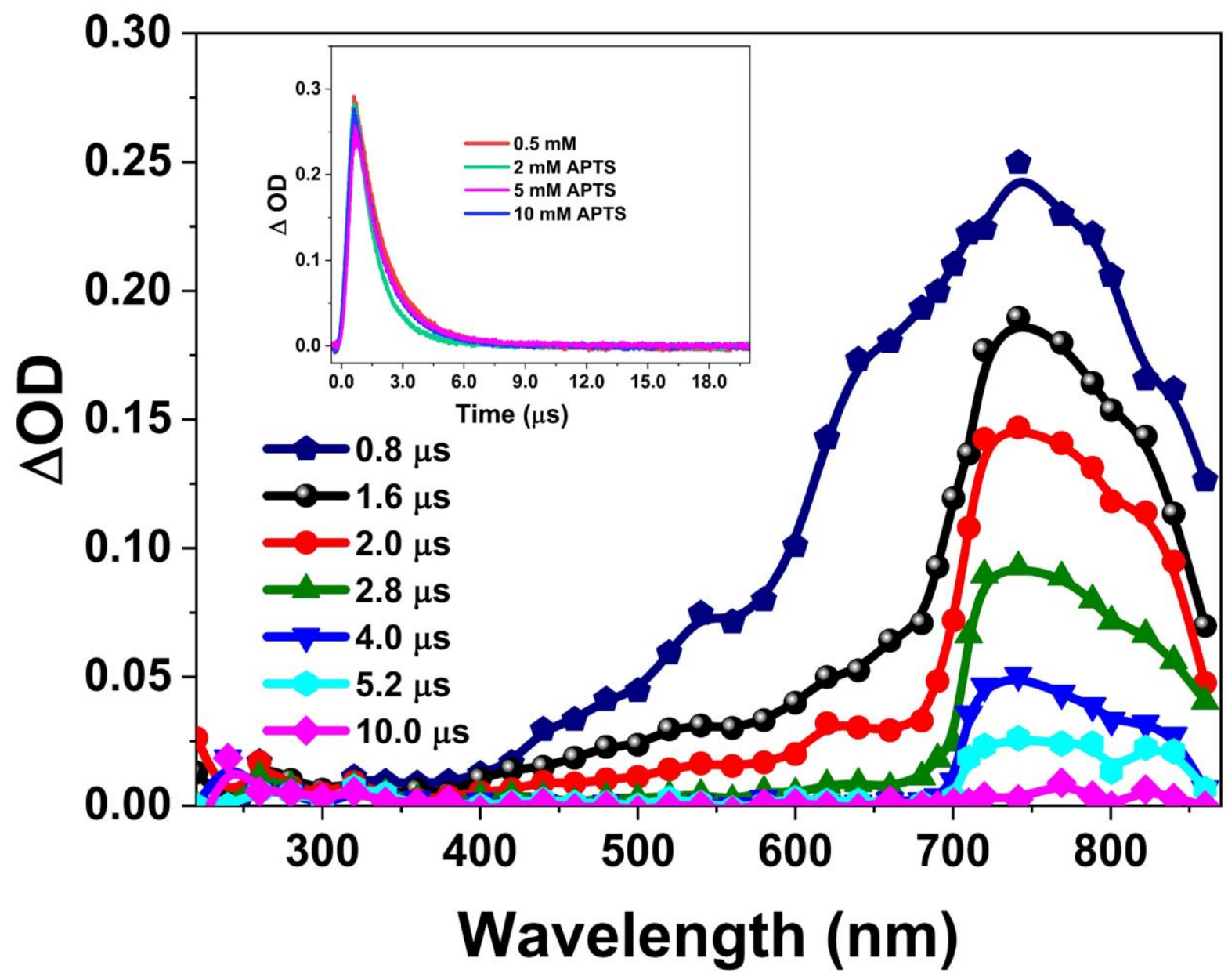

Fig.S6. Time-resolved absorption spectrum of APTS $(5.6 \mathrm{mM})$ dissolved in nanopure water. In this solution, tert-butanol $(1 \mathrm{M})$ was added to observe the exclusive reaction of $\mathrm{e}_{\text {sol }}^{-}$with the APTS (as $\mathrm{H}^{\bullet}$ and ${ }^{\circ} \mathrm{OH}$ gets quenched by tertbutanol). The experimental parameters involve 500 ns e-beam pulse, $\sim 48 \mathrm{~Gy}, \mathrm{~N}_{2}$ bubbled. Inset shows the decay traces of the $\mathrm{e}_{\text {sol }}^{-}$(at $700 \mathrm{~nm}$ ) recorded at various concentrations of APTS. 


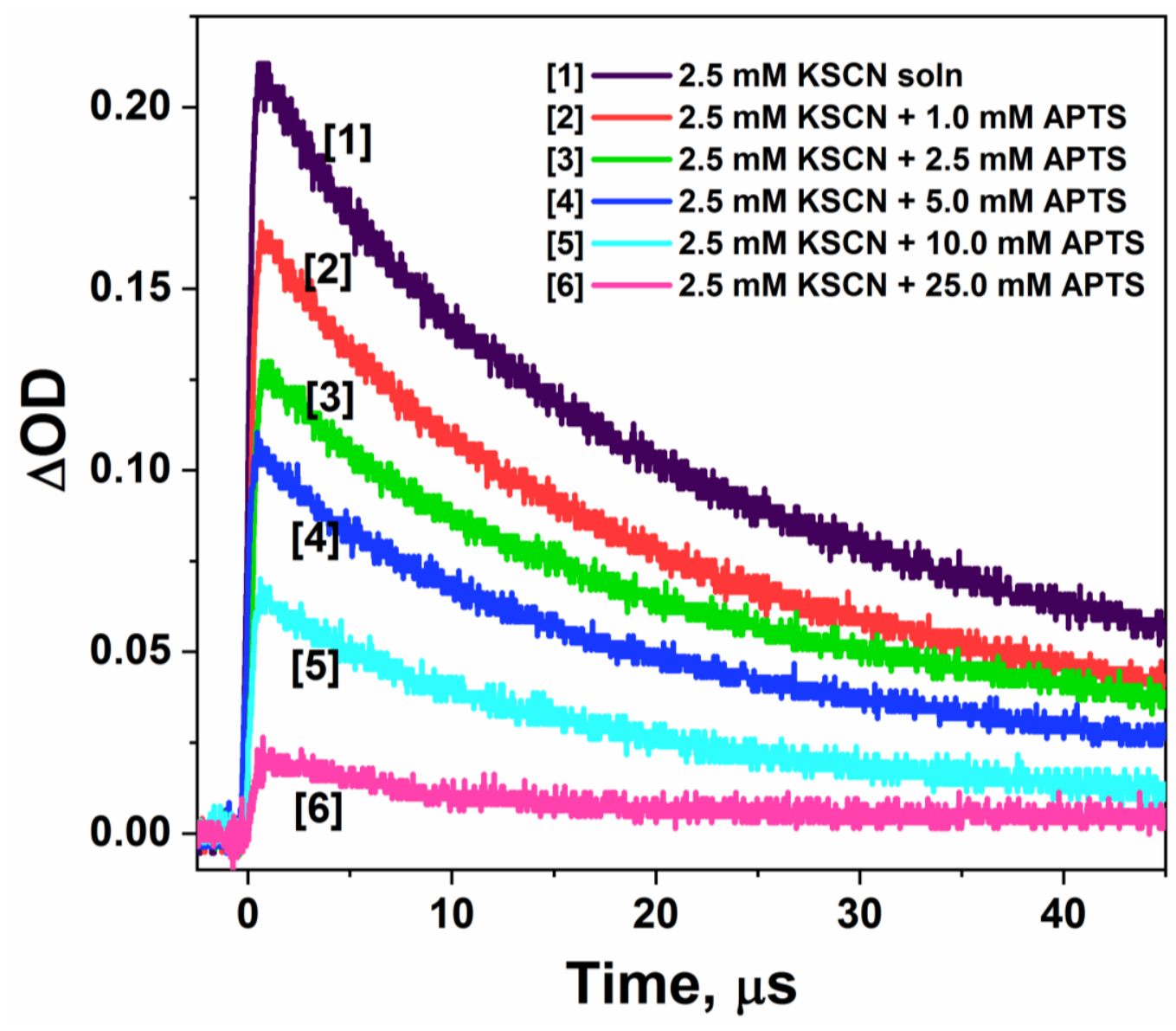

Fig.S7. Kinetic decay traces (at $475 \mathrm{~nm}$ ) of $\mathrm{KSCN}(2.5 \mathrm{mM})$ in the presence of APTS with varying concentration.

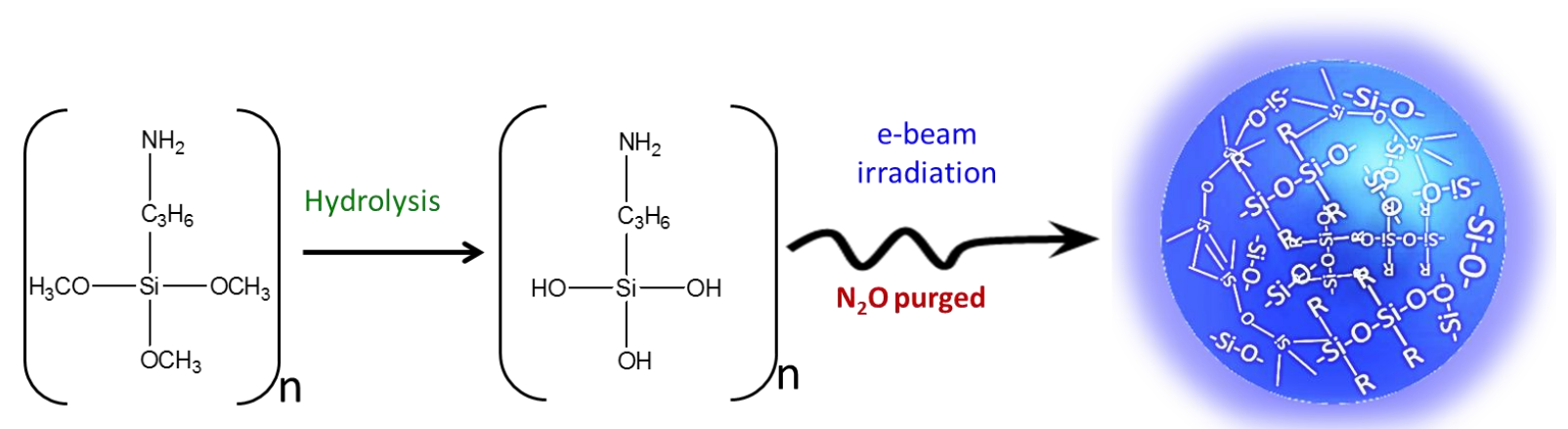

Fig.S8. Schematic representation of the formation of OSiNPs by electron beam irradiation. 

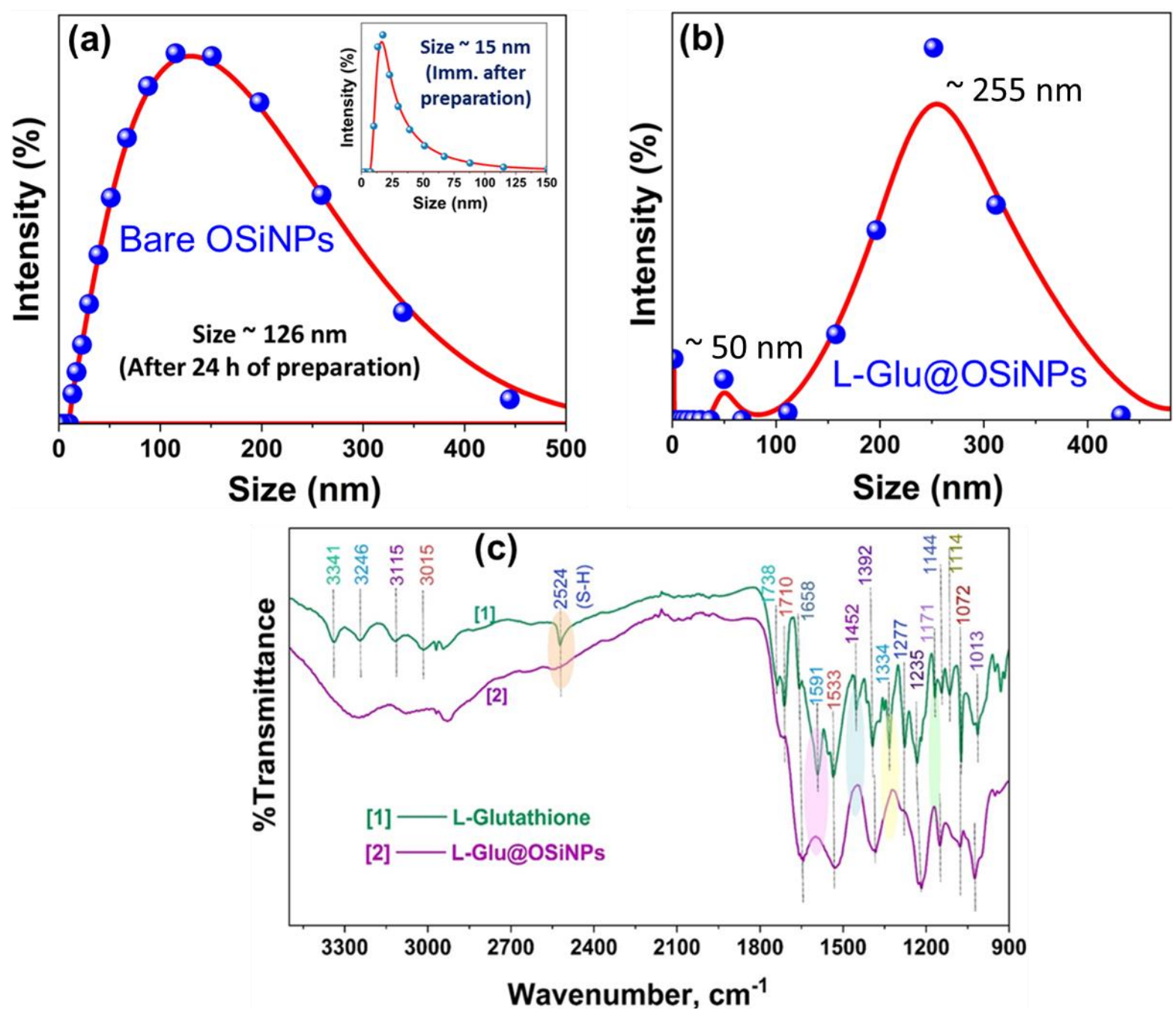

Fig.S9. (a) DLS size distribution of bare OSiNPs after $24 \mathrm{~h}$ of preparation, while inset shows size distribution of NPs recorded immediately after the preparation; (b) DLS size distribution of L-Glu@OSiNPs; (c) FTIR spectra of L-glutathione (powder form) and L-glutathione functionalized OSiNPs (L-Glu@OSiNPs). 

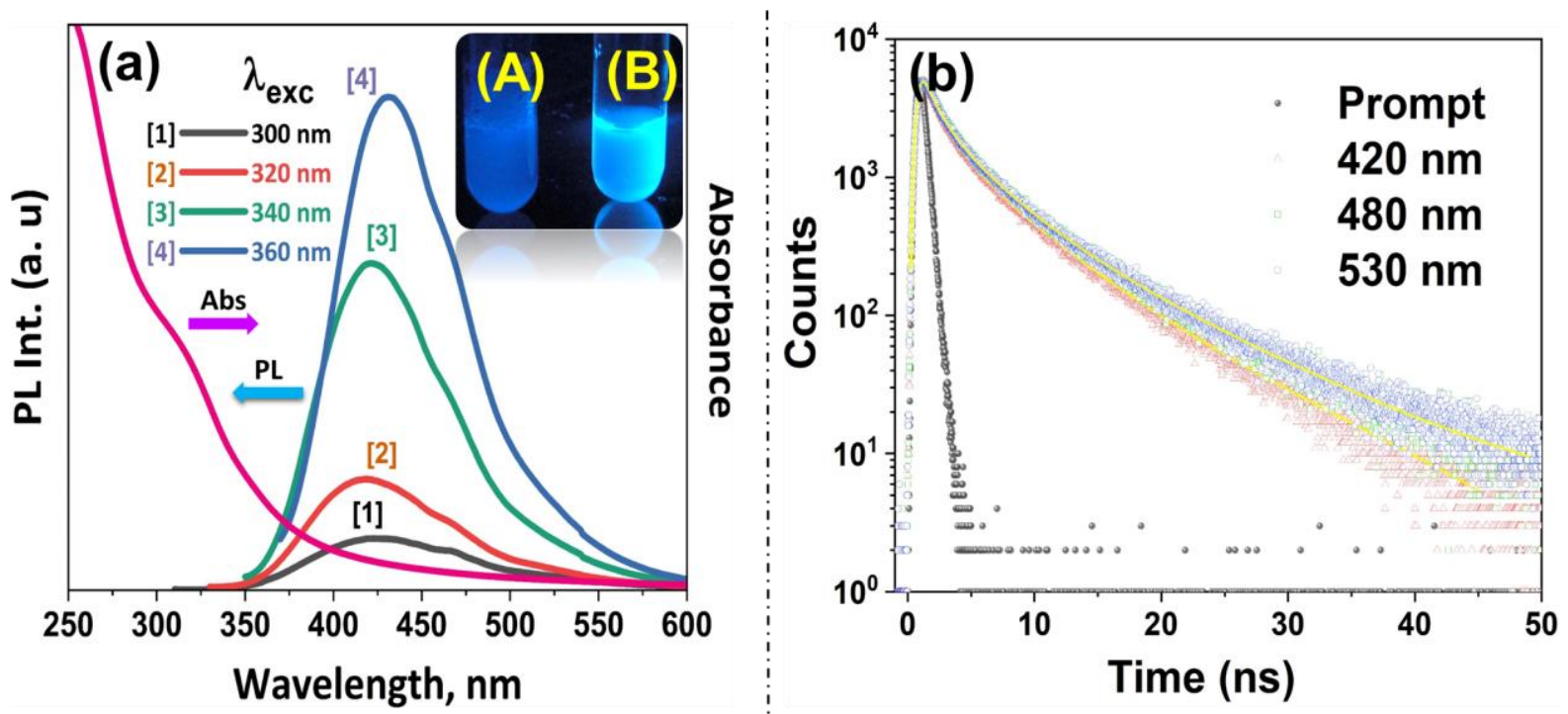

Fig.S10. (a) Absorption and excitation-wavelength-dependent PL spectra of LGlu@OSiNPs. Inset: Picture showing the photo of the colloidal solutions of OSiNPs (A) and L-Glu@OSiNPs (B) under UV light; (b) Room temperature PL temporal decay curves $\left(\lambda_{\mathrm{ex}}=339 \mathrm{~nm}\right)$ for L-Glu@OSiNPs at different emission wavelengths, along with the IRF (prompt) and the best fit. 


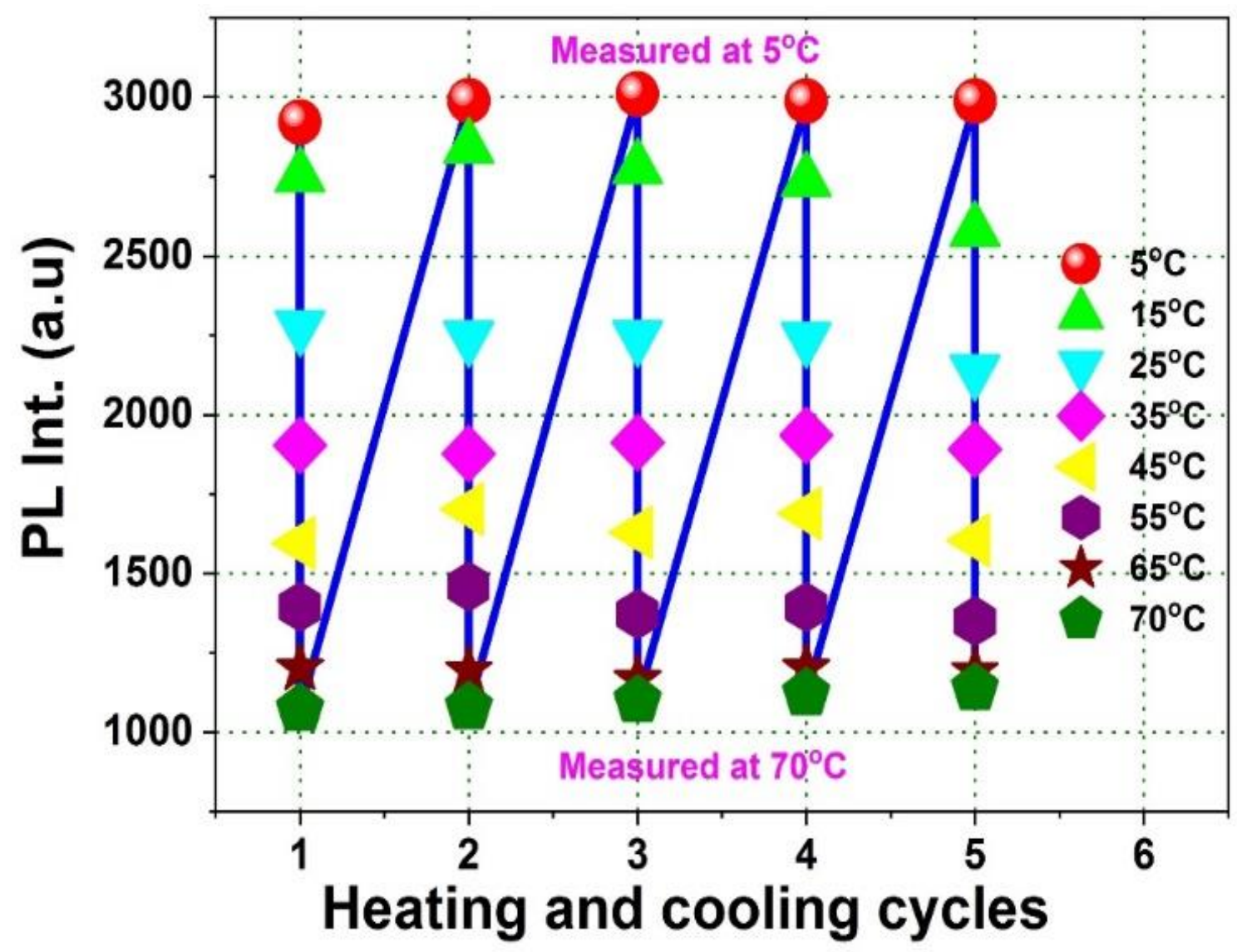

Fig.S11. Plot showing the reproducibility in the PL intensities of OSiNPs $\left(\lambda_{\mathrm{ex}}=\right.$ $360 \mathrm{~nm}$ ) even after 5 heating and cooling cycles of temperature variation from 5 to $70{ }^{\circ} \mathrm{C}$.
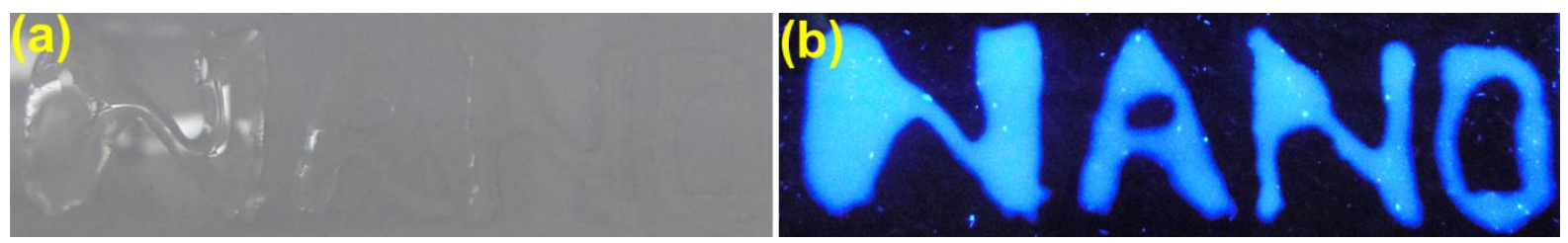

Fig.S12. Photos (a) and (b) taken under normal room light and UV light, respectively, shows the word 'NANO' marked on a glass slide with the asprepared L-Glu@OSiNPs. These words could be seen clearly under the UV light. 

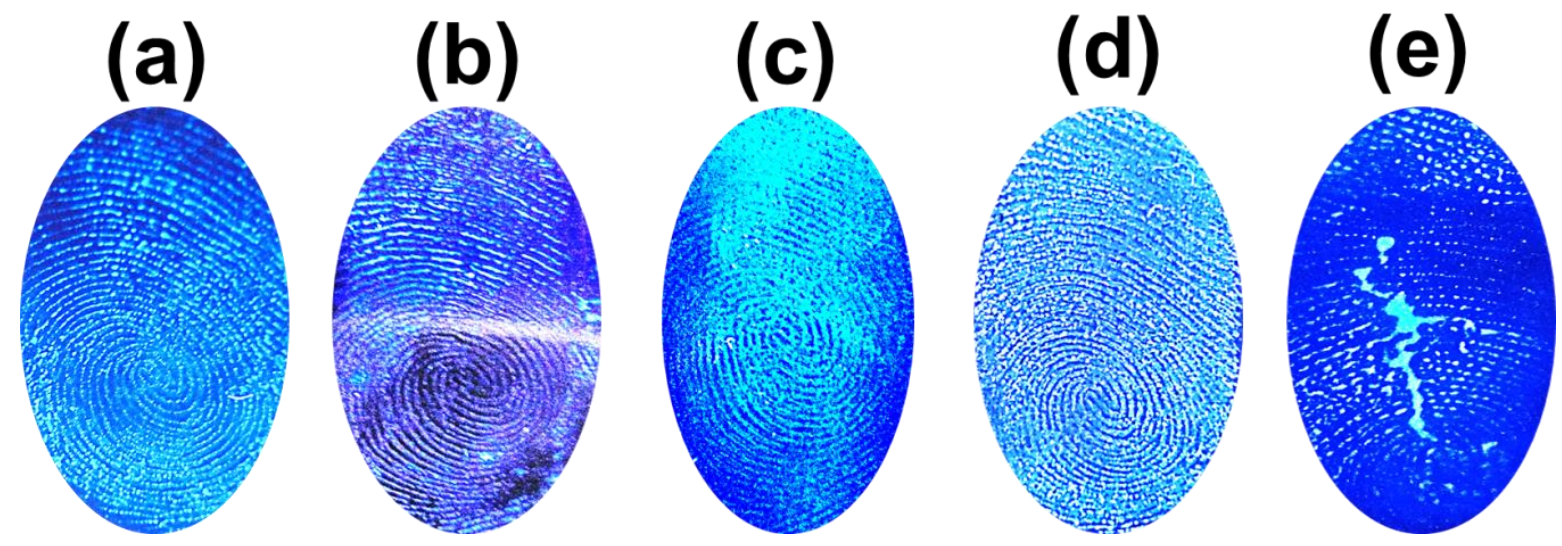

Fig.S13. Photographs of fingerprints (under UV light) developed with LGlu@OSiNPs on various objects: (a) aluminium foil, (b) glass cup, (c) CD/DVD, (d) aluminium metal sheet, (e) plastic cover of a CD/DVD.

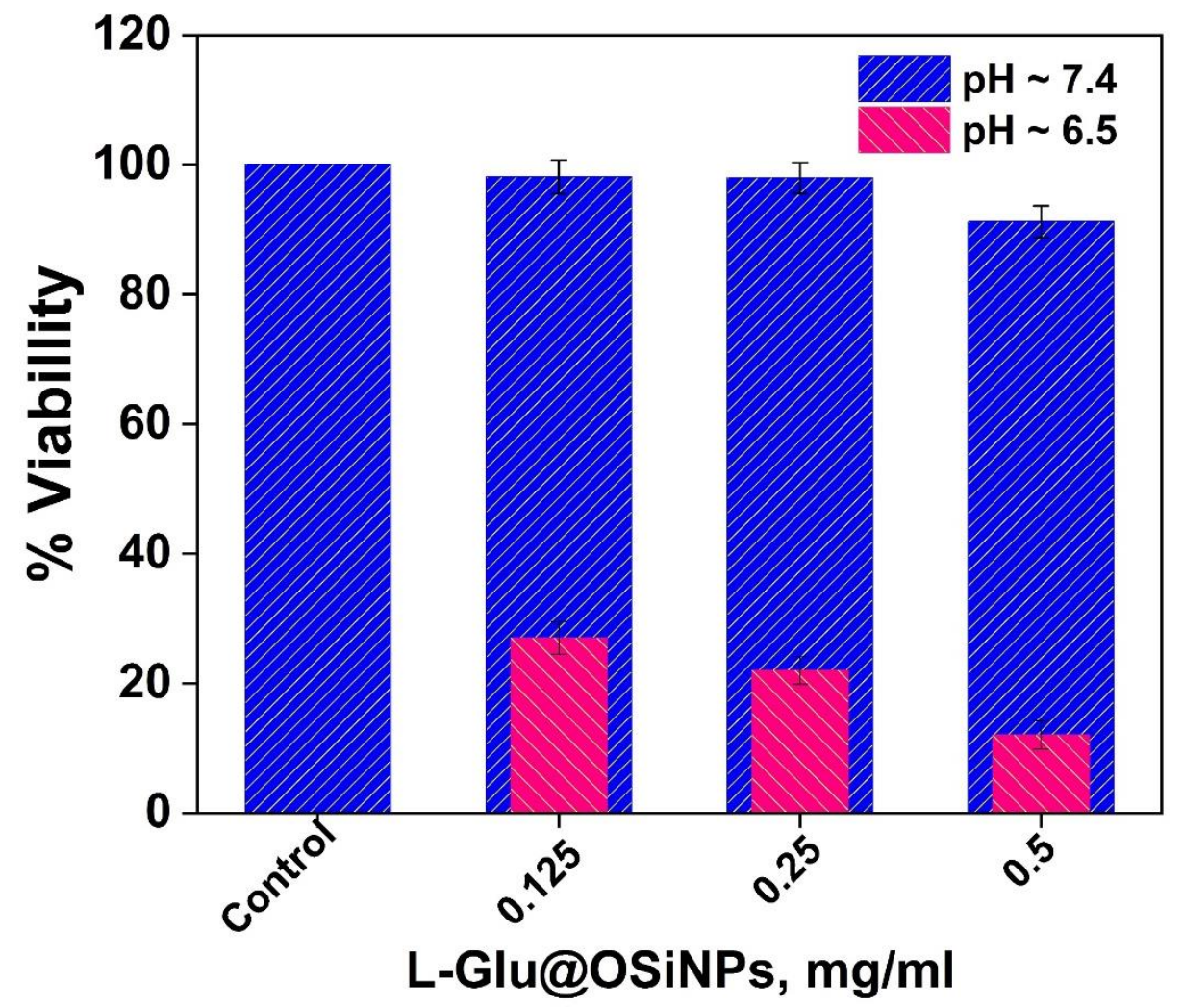

Fig.S14. The cytotoxic effects of the increasing concentrations of LGlu@OSiNPs of varying pH $\sim 6.5$ and $~ 7.4$ in $\mathrm{CHO}$ cells after $48 \mathrm{~h}$ of incubation by MTT assay. Values are mean $\pm \operatorname{SEM}(n=3)$. 


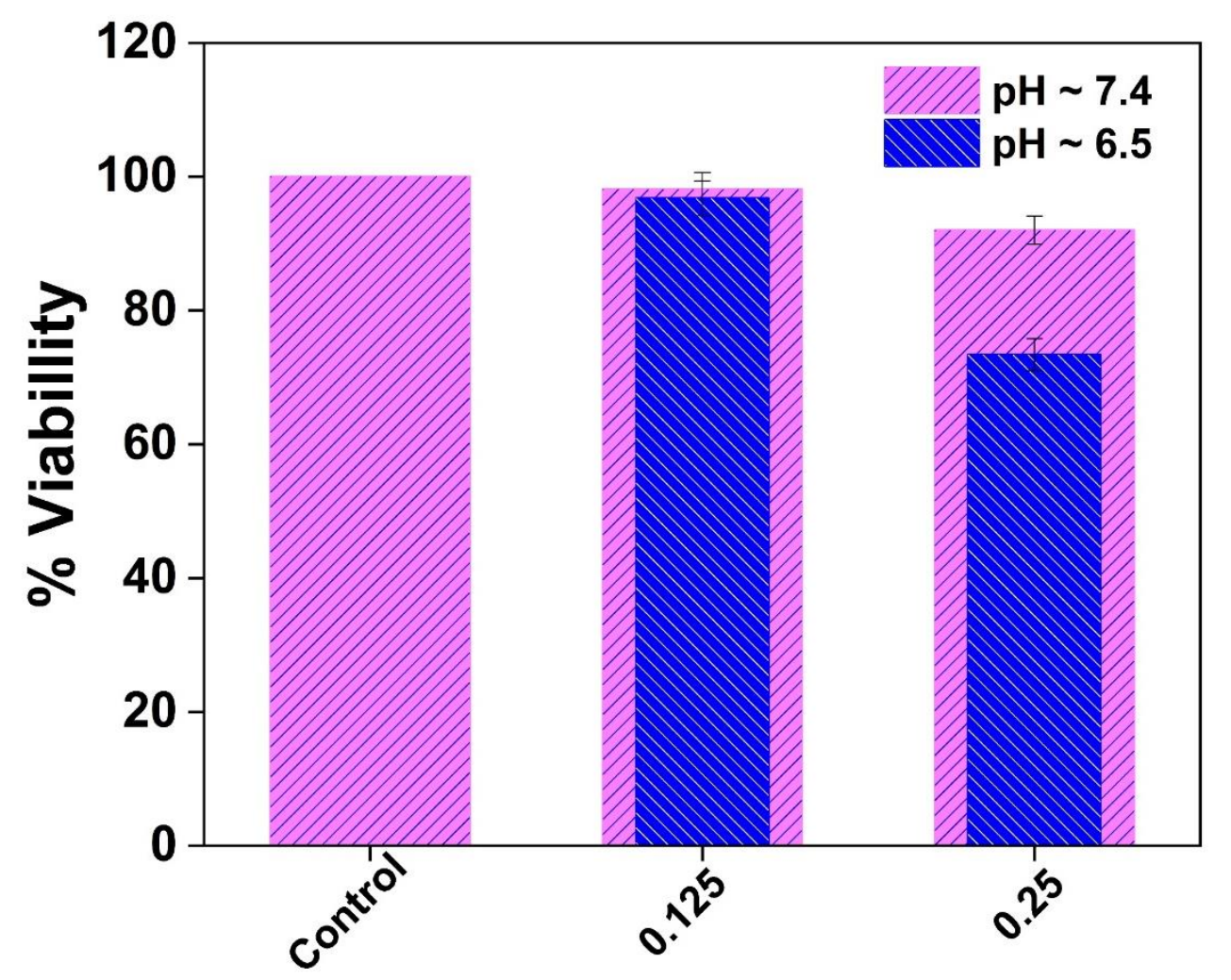

L-Glu@OSiNPs, mg/ml

Fig.S15. The cytotoxic effects of the increasing concentrations of LGlu@ OSiNPs of varying pH $\sim 6.5$ and $\sim 7.4$ in A549 cells after $48 \mathrm{~h}$ of incubation by MTT assay. Values are mean $\pm \operatorname{SEM}(n=3)$. 